\title{
THE DESIGN OF 4-LEVEL IMPELLER ON CENTRIFUGAL COMPRESSOR ASSISTED CF TURBO SOFTWARE
}

\author{
Ricky Gunawan Budianto, Sufiyanto*, Boe Tong Widada \\ Department of Mechanical Engineering, University of Merdeka Malang \\ *Email corresponding author: sufiyanto@unmer.ac.id
}

\begin{abstract}
Compressor is a compressing device or compressing air in other words a compressor is a compressed air generator. Because of the compression process, air has a higher pressure compared to environmental air pressure $(1 \mathrm{~atm})$. In this Final Project the compressor is planned with an output pressure of $140 \mathrm{bar}$, a flow rate of $5000 \mathrm{~m} 3 / \mathrm{hr}, 4$ levels, a shaft rotation of $15000 \mathrm{rpm}$. In the compressor planning, TURBO $10 \mathrm{CF}$ software is used. Input from the software is the flow rate and pressure of each level. As output is the impeller diameter, the output pressure of each impeller. Power of each level. The average impeller diameter is $596 \mathrm{~mm}$. The air coming out of each level is cooled. The cooling system is not planned in the final project.
\end{abstract}

Key words: Compressor, CF TURBO, Pressure, compressed air.

\section{INTRODUCTION}

In the current millennial era, science and technology are increasingly developing in the field of science and technology. In its development, the industrial world is very much needed and the compressor is used as a tool to help increase the pressure of compressed fluids such as air and gas. The type of compressor must be in accordance with its use and placement. One example that is used is a centrifugal compressor where the centrifugal compressor is a type of dynamic compressor.

The objective of this research is to plan a compressor with an air volume of $5000 \mathrm{~m}^{3} /$ hour and an output pressure of 140 bar.

1. The size of the impeller diameter of each level

2. The output pressure of each level

3. Shape and number of impeller blades of each level

4. Power each level

5. The output temperature of each level

\section{Density}

The benefit to be achieved from compressor planning is that students understand better machines in industry, in this case, the compressor. 


\section{Limited Research}

1. Does not discuss the thermodynamic process on the compressor

2. Does not discuss machine installation and inspection techniques

3. Does not make/manufacture compressors.

4. Does not discuss the calculation of the finite element method for fluid flow in a centrifugal compressor

5. Does not address balancing issues

6. Does not address critical rotation.

\section{METHODOLOGY}

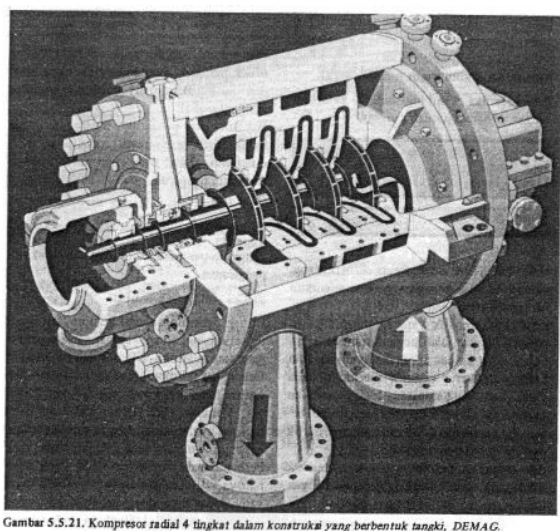

Figure 1 Example of a Centrifugal Compressor

\section{Research Flowchart}

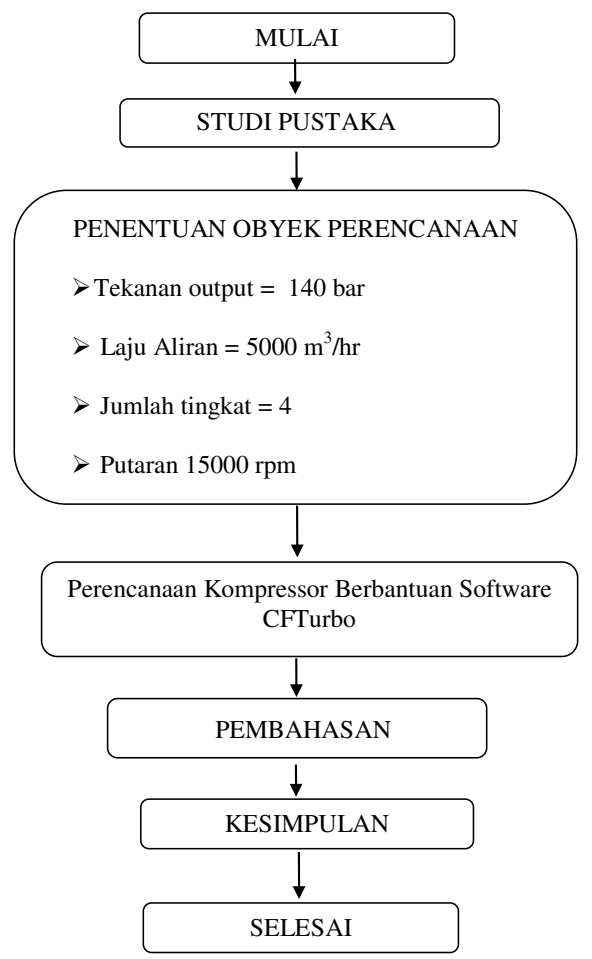

Figure 2 Research flowchart

Air flow rate $=5000 \mathrm{~m}^{3} /$ hour

Number of levels $=4$ levels

Total air pressure $=140$ bar

Rotation $=15000 \mathrm{rpm}$

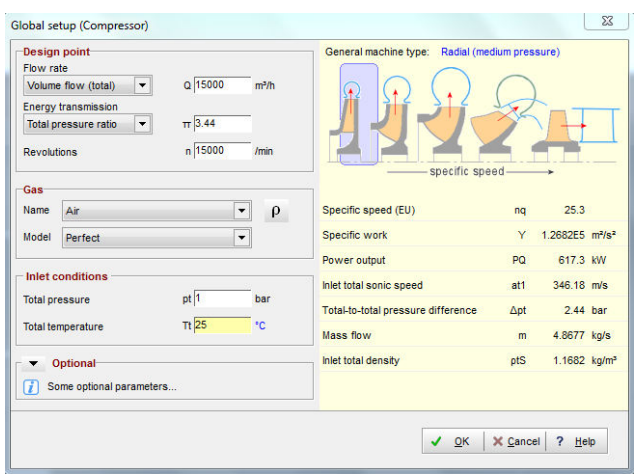

Figure 3 Initial Display 
The Design on CF TURBO

$\cdot$

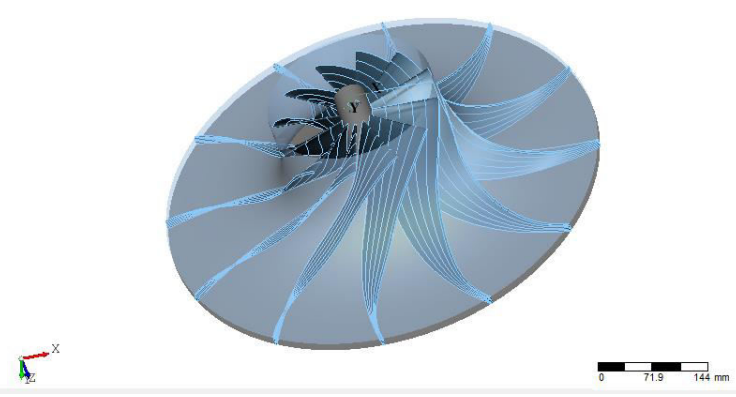

Figure 4 The results of Impeller planning using CF TURBO

Table 1. Data Information for Each Level of Impeller Planning

\begin{tabular}{|c|c|c|c|c|}
\hline & $\begin{array}{c}\text { Tingkat } \\
1\end{array}$ & $\begin{array}{l}\text { Tingkat } \\
2\end{array}$ & $\begin{array}{l}\text { Tingkat } \\
3\end{array}$ & $\begin{array}{c}\text { Tingkat } \\
4\end{array}$ \\
\hline Tekanan Input (bar) & 1 & 3,44 & 11,83 & 40,7 \\
\hline Tekanan Output (bar) & 3,44 & 11,83 & 40,7 & 140 \\
\hline Beda Tekanan & 3,44 & 3,44 & 3,44 & 3,44 \\
\hline Putaran (rpm) & 15000 & 15000 & 15000 & 15000 \\
\hline $\begin{array}{l}\text { Laju Aliran Udara ( } \\
\mathrm{m} 3 / \mathrm{jam})\end{array}$ & 5000 & 5000 & 5000 & 5000 \\
\hline $\begin{array}{l}\text { Temperatur Input ( } \\
\left.{ }^{\circ} \mathrm{C}\right)\end{array}$ & 25 & 50 & 60 & 70 \\
\hline $\begin{array}{lr}\text { Temperatur } & \text { Output } \\
\left({ }^{\circ} \mathrm{C}\right) & \text { Tanpa } \\
\text { Pendinginan } & \\
\end{array}$ & 174,5 & 183 & 260 & 279 \\
\hline $\begin{array}{lr}\text { Temperatur } & \text { Output } \\
\left({ }^{\circ} \mathrm{C}\right) & \text { Dengan } \\
\text { Pendinginan } & \\
\end{array}$ & 50 & 60 & 70 & 80 \\
\hline $\begin{array}{l}\text { Berat Jenis Input ( } \\
\mathrm{kg} / \mathrm{m} 3)\end{array}$ & 1,14 & 3,68 & 12,306 & 41,098 \\
\hline $\begin{array}{l}\text { Berat Jenis Output ( } \\
\mathrm{kg} / \mathrm{m} 3)\end{array}$ & 2,07 & 6,40 & 21,322 & 71,059 \\
\hline $\begin{array}{l}\text { Diameter Impeller } \\
(\mathrm{mm})\end{array}$ & 566 & 596 & 606 & 616 \\
\hline $\begin{array}{l}\text { Suction } \\
(\mathrm{mm})\end{array}$ & 212 & 226 & 240 & 262 \\
\hline Power Output (kW) & 205,8 & 708 & 2434,4 & 8375 \\
\hline Diameter Poros $(\mathrm{mm})$ & 42,2 & 64 & 97,1 & 147,1 \\
\hline $\begin{array}{l}\text { Volume Spesifik } \\
\text { Input }\left(\mathrm{m}^{3} / \mathrm{kg}\right)\end{array}$ & 0,87 & 0,27 & 0,08 & 0,02 \\
\hline $\begin{array}{l}\text { Volume Spesifik } \\
\text { Output }\left(\mathrm{m}^{3} / \mathrm{kg}\right)\end{array}$ & 0,48 & 0,15 & 0,04 & 0,01 \\
\hline Jumlah Sudu & 12 & 12 & 12 & 12 \\
\hline
\end{tabular}

Average impeller diameter $=$

$(566+596+606+616) / 4=596 \mathrm{~mm}$

\section{CONCLUSION}

In planning for centrifugal compression assisted by CF Turbo software, the impeller diameter,
Total power $=(206+708+2434+8375)$

$$
=11623,3 \mathrm{~kW}=11,6 \mathrm{MW}
$$

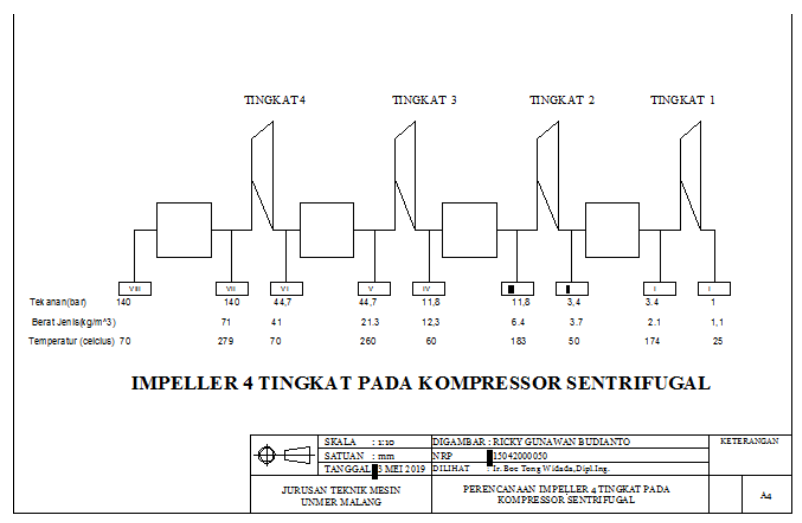

Figure 5 Autocad Schematic of a 4 Level Impeller Planning

impeller shape, and the temperature of the air that comes out of each level are obtained. The air is cooled before being put to the next level. 
For an air flow rate of $5000 \mathrm{~m}^{3} /$ hour, a shaft rotation of $15000 \mathrm{rpm}$, a total power of 11.6 MW is required. This power is the sum of each power.

\section{REFERENCES}

Dixon, Larry S., Hall, Cesare , 2010, Fluid Mechanics and Thermodynamics of Turbomachinery Butterworth Heinemann

Helvoirt, van, J. ,2007, Centrifugal Compressor Surge Modeling And Identification For Control

Eindhoven:,Technische Universiteit Eindhoven

Leufvén, Oskar, 2013, Modeling For Control Of Centrifugal Compressors, Department of Electrical Engineering Linköpings universitet, SE58183 Linköping, Sweden

Reynolds, William C., Perkins, Henry C, 1996, Termodinamika Teknik ,terjemahan Filino Harahap, Penerbit Erlangga, Jakarta.

Shapiro, Howard N. 2004, Termodinamika Teknik , Alih BahasaYulianto Sulistyo Nugroho, Penerbit Erlangga, Jakarta.

Shigley, Joseph E., and Mitrchell Larry D., 1994 Perencanaan Teknik Mesin , Penerbit Erlangga, Jakarta.

Suga, Kiyokatsu dan Sularso, 1994 Dasar Perencanaan dan Pemilihan Elemen
Mesin,Penerbit Pradnya Paramita, Jakarta

Streeter, Victor L.. Benjamin Wylie. Fluid mechanics, Toronto : McGraw-Hill Ryerson, 1981 